\title{
ENVOLVIMENTO NOS DIREITOS HUMANOS E SISTEMAS DE VALORES ${ }^{1}$
}

\author{
Cícero Pereira* \\ Ana Raquel Correia Ribeiro" \\ Sandro José Cardoso"
}

\begin{abstract}
RESUMO. Com base no modelo da análise quantitativa das representações sociais, o estudo $(N=300)$ tratou do posicionamento de estudantes universitários em relação aos Direitos Humanos (DHs) e à ancoragem social desse posicionamento nos sistemas de valores dos estudantes. Os resultados mostram que as representações dos estudantes sobre o envolvimento nos DHs envolvem quatro princípios organizadores: pessoal-abstrato; pessoal-concreto; governamentalabstrato; governamental-concreto. Em relação à ancoragem social dos princípios organizadores do envolvimento nos DHs, observou-se que os valores pós-materialistas se relacionaram positivamente com o envolvimento pessoal-abstrato, enquanto a adesão aos valores religiosos implicou maior envolvimento no princípio pessoal-concreto. Além disso, a adesão aos valores materialistas levou a uma avaliação mais positiva do envolvimento do Governo Brasileiro nos DHs, ao passo que os valores pós-materialistas contribuíram com uma avaliação mais crítica desse governo. As discussões abordam a centralidade dos valores na formação das representações sociais dos DHs.
\end{abstract}

Palavras-chave: representações sociais, direitos humanos, sistemas de valores.

\section{INVOLVEMENT IN HUMAN RIGHTS AND VALUE SYSTEMS}

\begin{abstract}
Based on the quantitative analysis model of social representations, a study $(N=300)$ was carried out concerning the opinion of university students on Human Rights (HR), and the social link of this positioning in the students system of values. The results show that the students representations of the involvement in HR comprise four organizing principles: personal-abstract; personal-concrete; governmental-abstract; governmental-concrete. With regard to the social anchorage of the organizing principles of involvement in HR, it has been observed that post-materialist values were positively related to the involvement personal-abstract, whereas adherence to religious values implied a greater involvement in the personal-concrete principle. In addition, adherence to materialist values led to a more positive appraisal of the Brazilian Government involvement in HR, while the post-materialist contributed to a more critical evaluation of the Government. These results are discussed stressing the core of social values in the formation of HR social representations.
\end{abstract}

Key words: Social representations, human rights, value systems.

\section{INTRODUÇÃO}

Os Direitos Humanos (DHs) são um conjunto de normas institucionalizadas pela Organização das Nações Unidas (ONU). Seu objetivo é regular as relações entre os estados e os indivíduos (Cranston, 1979). Mesmo sob a vigência da Declaração Universal dos Direitos Humanos (DUDH), diariamente esses direitos são violados (Pereira, 2000). No entanto, mesmo com o aumento no número de organizações não-governamentais e de grupos que lutam pela defesa dos direitos das minorias, o cidadão comum tem apoiado abertamente a violação de direitos fundamentais (Cardia, 1995; Souza, 1996; Souza \& cols., 1998). Mas quais são as variáveis psicossociais subjacentes ao posicionamento das pessoas frente aos DHs? Considerando os DHs como a materialização de um conjunto de expectativas concernentes aos valores

1 Pesquisa realizada com recursos da Vice-Reitoria de Pós-Graduação e Pesquisa da Universidade Católica de Goiás. Os autores agradecem a Ana Raquel Rosas Torres e aos membros do Grupo de Pesquisa em Processos Grupais pelos valiosos comentários à pesquisa apresentada neste artigo.

* Docente no Departamento de Psicologia da Universidade Católica de Goiás-UCG e doutorando em Psicologia Social no Instituto Superior de Ciências do Trabalho e da Empresa (Lisboa, Portugal).

\# Psicóloga e ex-bolsista de iniciação científica da Universidade Católica de Goiás-UCG.

II Psicólogo e ex-bolsista de iniciação científica da Universidade Católica de Goiás-UCG. 
inerentes à natureza humana (Camino, 2000), qual seria o papel desses valores, na visão que as pessoas têm desses direitos? Seguindo esse raciocínio, como os valores sociais orientam o envolvimento das pessoas nos DHs e qual a avaliação que eles fazem do envolvimento do governo? Esses questionamentos colocam em evidência o debate sobre a responsabilidade pela aplicação dos DHs: quem é o responsável pela aplicação desses direitos: os indivíduos, ou o Estado Brasileiro? Especificamente, a quem os cidadãos atribuem essa responsabilidade? Independentemente de como seja colocada a questão, o que se apresenta como relevante em um estudo no âmbito da Psicologia Social sobre esse tema é saber como os grupos sociais representam os responsáveis pela aplicação dos DHs. Este artigo, baseado na perspectiva introduzida por Moscovici (1978) sobre as representações sociais, investiga como estudantes universitários representam seu envolvimento e o do Governo Brasileiro nos DHs e como essas representações se ancoram nos sistemas de valores desses estudantes.

\section{REPRESENTAÇÕES SOCIAIS E DIREITOS HUMANOS}

Segundo Moscovici (1978), representações sociais são o "sistema de valores, noções e práticas que proporcionam aos indivíduos os meios para orientar-se no contexto social e material (...) um corpo organizado de conhecimentos e uma das atividades psíquicas graças à qual os homens tornam inteligíveis a realidade física e social" (p. 79). Esse conceito, ao inaugurar a perspectiva das representações sociais, passa a ser utilizado para explicar uma ampla variedade de fenômenos sociais. Contudo, essa perspectiva tem sido criticada tanto em seus aspectos conceituais (Jahoda, 1988; Potter \& Linton, 1985) quanto metodológicos (Leyens \& Dardene, 1996), tendo sido as críticas sistematicamente rebatidas (Moscovici, 1988).

As críticas referem-se às ambigüidades da definição utilizada por Moscovici (1978) para descrever as representações, fundamentalmente no que concerne ao fato de seu conceito ser idêntico aos de outros construtos estudados na Psicologia Social, tais como os de sistemas de valores, atitudes, crenças, ideologia (Álvaro, 1995). Essa ambigüidade levou Billig (1991) a propor que os teóricos dessa perspectiva devem também explicar o que não é representação social. Uma definição mais objetiva do que a proposta por Moscovici é apresentada por Jodelet (1989), segundo a qual representação social é "uma modalidade de conhecimentos, socialmente elaborada e compartilhada, com o objetivo prático que contribui para a construção de uma realidade comum a um conjunto social" (p. 36). Outra abordagem, que é bastante conhecida no Brasil, é proposta por Abric (1994) para explicar a estrutura das representações. Para este autor, as representações sociais são organizadas em torno de um núcleo central formado por modalidades de conhecimentos compartilhados. Esse núcleo pode ser comparado aos esquemas cognitivos, em que o conteúdo representacional seria o resultado de uma organização psicológica compartilhada pelos indivíduos de um ambiente social (Pereira \& Soares, 2003). As abordagens propostas por Jodelet e por Abric, mesmo apresentando concepções mais objetivas do que a proposta por Moscovici (1978), caracterizam as representações com base em sua natureza consensual. Contudo, a ênfase nessa característica apresenta um certo grau de contradição com as conclusões de Moscovici relativas às representações da psicanálise (Pereira \& Soares, 2003).

No estudo de Moscovici (1978), três relacionamentos comunicativos foram analisados: jornais de grande circulação, imprensa do Partido Comunista, e imprensa da Igreja Católica. Os resultados mostraram que, a partir do contexto social (os diferentes sistemas comunicativos), as pessoas utilizaram diferentes formas de operações cognitivas e de regras de inferências para compreender e explicar o objeto representado (a psicanálise). Esses resultados levaram Moscovici a concluir que os três sistemas comunicativos mantêm sua singularidade. Essa conclusão é central à compreensão da natureza das representações sociais, porque subjacente a ela encontra-se a idéia de que as definições de representações sociais, em termos consensuais, são insuficientes (Doise, 1993). Nesse sentido, Doise (1986) descreve de forma menos ambígua a natureza dessas representações. Esse autor as define como princípios organizadores dos posicionamentos dos indivíduos e dos grupos sociais em relação aos elementos que formam o campo representacional. Essa definição introduz a noção de variabilidade como característica central às representações e, por conseguinte, apresenta-se como a definição mais congruente com as conclusões de Moscovici e com a concepção de representações como construtos psicossociais subjacentes à natureza dos estímulos e das alternativas de respostas correspondentes a esses estímulos (Pereira \& Soares, 2003).

Com base nessa definição, Doise, Clémence \& Lorenzi-Cioldi (1993) propuseram um modelo para a 
análise quantitativa das representações sociais, o qual avalia os três aspectos principais dessas representações: a organização do campo representacional; os princípios organizadores das diferenças individuais; a ancoragem social dos princípios organizadores. A organização do campo representacional refere-se ao processo de objetivação (Moscovici, 1978). Os estudos que se concentram nesse aspecto procuram encontrar uma percepção compartilhada sobre um objeto social. Contudo, o conceito de princípios organizadores baseia-se na variabilidade das representações e analisa as dimensões subjacentes aos diferentes posicionamentos dos indivíduos no campo representacional. A ancoragem social identifica como as pertenças sociais e os discursos identitários e ideológicos se organizam para definir as representações que as pessoas constroem.

Com base no modelo para a análise quantitativa das representações sociais, um grupo de pesquisadores da Universidade de Genebra vem desenvolvendo um programa de investigação sobre os DHs (Doise \& Herrera, 1994; Doise, Staerklé, Clémence \& Savory, 1998). Em síntese, eles mostram que as representações dos DHs reproduzem os debates ocorridos na ONU que levaram à elaboração da DUDH (Pereira \& Camino, no prelo). Esses estudos evidenciam que o posicionamento dos grupos sociais nos DHs não é aleatório nem uniformemente distribuído. Os grupos são organizados com base em três categorias de direitos estabelecidas nas definições institucionais desses direitos, principalmente as proclamadas na DUDH (Doise \& Hererra, 1994): direitos fundamentais; direitos socioeconômicos; direitos individuais. Os posicionamentos dos grupos sociais nos direitos estão ancorados na inserção sociopolítica dos membros desses grupos. De fato, as preferências ideológicas influenciam o posicionamento dos indivíduos em relação a esses direitos: o posicionamento favorável à aplicação dos DHs está ancorado na identificação política de esquerda e na rejeição aos partidos de direita com ideologia autoritária e conservadora. Mas como os grupos sociais representam o seu próprio envolvimento e o do governo nesse processo?

Para avaliar esse problema, Spini e Doise (1998) apresentam um estudo sobre os princípios organizadores das representações que universitários suíços têm do envolvimento nos DHs. Esses autores constatam uma representação organizada em duas dimensões: pessoal versus governamental; abstrato versus concreto. A primeira dimensão descreve o sujeito da responsabilidade pelo cumprimento dos direitos: Estado versus cidadão. A segunda dimensão organiza os posicionamentos concernentes ao nível do compromisso: concreto (aquilo que atualmente se está fazendo); abstrato (o que deveria ser feito). Segundo Spini e Doise (1998), essa dimensão é responsável por separar o que os indivíduos deveriam fazer daquilo que eles concretamente fazem pelos DHs. A articulação entre as duas dimensões configura quatro formas de representação do envolvimento nos DHs: governamental-abstrato (aquilo que o governo deveria fazer); governamental-concreto (a percepção do que o governo está concretamente realizando); pessoalabstrato (aquilo que o indivíduo deveria fazer); pessoal-concreto (o que o indivíduo está realizando concretamente). Spini e Doise (1998) também mostram que os universitários suíços consideram que o governo de seu país deveria se envolver mais do que eles próprios na aplicação dos DHs; contudo, no nível concreto, os universitários acreditam que estão envolvidos na mesma proporção que o governo com a promoção desses direitos.

No Brasil, Camino, Camino, Pereira e Paz (no prelo) também identificam os quatros princípios organizadores do envolvimento nos DHs em uma amostra de universitários paraibanos. Eles verificam que a identificação partidária de esquerda relaciona-se com o sentimento de responsabilidade teórica com os DHs, enquanto a identificação de direita leva à redução do compromisso dos universitários com a aplicação concreta desses direitos. Em outra investigação, Pereira e Camino (no prelo) mostram que a representação do envolvimento nos DHs está ancorada na identificação ideológica de universitários paraibanos. Esses autores também verificam que a participação em atividades políticas de protesto contribui com o sentimento de responsabilidade por esses direitos. Além da identificação dos princípios organizadores do envolvimento nos DHs e de sua ancoragem no posicionamento político, é particularmente relevante investigar o papel de variáveis sociopolíticas relacionadas à essência dos DHs: os sistemas de valores. De fato, os valores são centrais à compreensão dos posicionamentos dos grupos sociais nos DHs (Herrera, Lavallée \& Doise, 2000; Pereira, 2000; Spini, 1997).

\section{SISTEMAS DE VALORES: NATUREZA E INFLUÊNCIA NOS DIREITOS HUMANOS}

Rokeach (1973) define os valores como crenças sobre comportamentos ou estados de existência desejáveis socialmente. Essa definição distingue valores instrumentais (os comportamentos) de valores 
terminais (o próprio desejável). Rokeach também analisa a influência de dois valores políticos (liberdade e igualdade) nas atitudes dos americanos diante das manifestações em defesa dos direitos civis. Ele constata que a adesão a esses valores é o principal organizador das atitudes frente aos direitos civis. Contudo, essa abordagem tem sido questionada, principalmente porque avalia o efeito isolado de um valor sobre as atitudes e comportamentos das pessoas. Para superar essa fragilidade, Schwartz (1992) define valores como metas transituacionais que expressam interesses concernentes a um tipo motivacional. Aqui, os valores não são mais analisados isoladamente, mais sim em tipos de valores. Schwartz identifica dez tipos motivacionais em vinte culturas: poder, realização, hedonismo, estimulação, autodireção, universalismo, benevolência, tradição, conformidade e segurança. Além disso, Schwartz (1994) verifica que esses tipos motivacionais organizam-se em torno de duas dimensões bipolares: abertura à mudança versus conservadorismo; autotranscendência versus autopromoção. Os critérios dessa organização são as possíveis relações de compatibilidade e conflito entre as metas motivacionais derivadas das necessidades básicas dos indivíduos (Schwartz \& Bardi, 2001).

Spini e Doise (1998) relacionam os dez tipos motivacionais com a representação que os estudantes de Genebra têm do envolvimento nos DHs. Eles constatam que os valores da autodireção, do universalismo e da benevolência correlacionam-se positivamente com o envolvimento pessoal (abstrato e concreto) e negativamente com a percepção de envolvimento governamental-concreto. Os valores de poder e de segurança correlacionam-se negativamente com o envolvimento pessoal-abstrato e positivamente com o envolvimento governamental-concreto. No conjunto, esses resultados mostram que a avaliação negativa do envolvimento do governo está ancorada em valores cujas metas motivacionais se constituem em fazer com que os indivíduos aceitem os outros como iguais a si e transcendam seus interesses egoísticos em função do bem-estar coletivo, bem como as metas que motivam esses indivíduos a lutarem pela liberdade de pensamento e de ação. Em contrapartida, a redução do sentimento de responsabilidade pessoal e a avaliação positiva do envolvimento do governo ancoram-se nos valores que têm como metas a promoção do status pessoal e o domínio sobre pessoas e recursos materiais.

A teoria de Schwartz (1992) tem apresentado fragilidades elementares. A principal delas é a necessidade de confirmação da universalidade da estrutura. Isso significa que, para que a essa teoria possa ser aplicável à análise dos valores humanos universais, os valores dos indivíduos em todas as sociedades deveriam ser organizados nos dez tipos motivacionais previstos pela teoria. De fato, as interpretações das relações entre os valores e as outras variáveis estudadas ficam comprometidas quando a cultura onde o estudo é realizado organiza os seus valores de maneira diferente da proposta na teoria. Mesmo estudada em várias culturas, a universalidade da estrutura e de seus conteúdos não tem sido confirmada (Pereira, Lima \& Camino, 2001). No que concerne à estrutura, Menezes e Campos (1997) verificam variações em função do desenvolvimento cognitivo dos indivíduos. No Brasil, Tamayo e Schwartz (1993) observam variações estruturais entre amostras de professores do ensino médio e de estudantes universitários. Recentemente, Pereira (2000) mostra que os valores de estudantes universitários estão organizados em apenas quatro tipos motivacionais. Com relação ao conteúdo, nesses estudos ocorrem divergências entre a localização constatada de muitos valores e a prevista na teoria. Além disso, Gouveia, Martínez, Meira e Milfont (2001) observam, através de uma análise fatorial confirmatória, que os tipos motivacionais não são organizados a partir de relações de conflito entre os valores. Suas relações são de compatibilidades. Mesmo com essas limitações, um pressuposto básico da teoria de Schwartz (1992) - a idéia de estudar tipos de valores - pode ser salvo, desde que seja integrado a uma abordagem menos psicologizante.

Nesse sentido, Pereira e cols. (2001) desenvolvem uma perspectiva de análise dos valores ao articular a idéia de estudar tipos motivacionais com a abordagem de Inglehart (1977) sobre os valores materialistas e pós-materialistas. Para viabilizar essa articulação, Da Costa (2000) define os sistemas de valores como estruturas de conhecimento socialmente elaboradas para sintetizar os elementos de um sistema simbólico amplamente compartilhado. Nesse sentido, os valores, organizados em sistemas, expressam os conflitos ideológicos que ocorrem nas sociedades, orientam os comportamentos e estão ancorados nas identidades dos grupos sociais e nos posicionamentos ideológicos derivados dessas identidades. Várias pesquisas têm sido realizadas com base nesses pressupostos. Seus objetivos são desenvolver um instrumento de medida, o Questionário de Valores Psicossociais (QVP), para avaliar os sistemas de valores e sua relação com as atitudes ideológicas dos grupos sociais (Lima \& Camino, 1995; Pereira \& cols., 2001). Com este instrumento, Pereira e cols. (2001) apresentam duas investigações em amostras de estudantes universitários 
paraibanos. Os resultados de uma análise de aglomerados e de um escalamento multidimensional revelam que os valores dos estudantes organizam-se em três sistemas: materialista; religioso; pósmaterialista. Posteriormente, Pereira, Camino, Da Costa, Lima, Lhullier e Sandoval (2001) mostram, em duas investigações em amostras de universitários da Região Sul do Brasil, uma organização dos valores igual à verificada nos estudos realizados na Paraíba.

Pereira (2000) apresenta a versão final do $Q V P$ (o $Q V P-24)$ ao acrescentar valores concernentes a um hipotético sistema hedonista, verificado em várias pesquisas (Schwartz, 1994). Ao aplicar o QVP-24, esse autor observa que os universitários paraibanos organizam seus valores com base em quatro sistemas: materialista, religioso, hedonista e pós-materialista. $\mathrm{O}$ sistema pós-materialista é constituído por três subsistemas: bem-estar individual; bem-estar social; bem-estar profissional. Ao correlacionar os sistemas de valores com os tipos motivacionais da teoria de Schwartz (1992), Pereira (2000) verifica convergências empíricas entre: materialismo e autopromoção; sistema religioso e conservadorismo; hedonismo e abertura à mudança; pós-materialismo e autotranscendência. Além disso, os sistemas de valores avaliados com o $Q V P-24$ ancoram de forma mais precisa o envolvimento nos DHs: os valores materialistas diminuem o envolvimento pessoal (abstrato e concreto) e aumentam a avaliação positiva do envolvimento do governo brasileiro. Em contrapartida, os valores pós-materialistas levam a uma visão mais crítica do governo e aumentam a percepção de que esse governo deve respeitar os DHs.

Em síntese, os estudos realizados com o QVP-24 mostram sua validade conceitual para a avaliação dos valores de estudantes universitários. Recentemente, esse instrumento tem sido validado em amostras de universitários goianos (Pereira, Torres \& Barros, 2002). A confiabilidade do instrumento também é elevada. Considerando todos os estudos realizados com o $Q V P$, os coeficientes alfa aplicados aos sistemas apresentam índices de fidedignidade que variam de 0,70 a $0,92(M=0,82 ; D P=0,06)$. Esses indicadores permitem utilizar esse instrumento numa investigação sobre como os valores ancoram os princípios organizadores do envolvimento nos DHs. O estudo investiga se estudantes universitários de Goiânia posicionam-se frente aos envolvimentos nos DHs com base nos princípios identificados em estudos anteriores (Pereira \& Camino, no prelo; Spini \& Doise, 1998): pessoal-abstrato; pessoal-concreto; governamental-abstrato; governamental-concreto; em seguida, analisa como os valores ancoram esses princípios. Embora não se tenha uma hipótese específica sobre como cada sistema ancora um ou outro princípio, espera-se que os valores materialistas e pós-materialistas sejam os determinantes dessa ancoragem. De fato, resultados de estudos anteriores indicam que a dimensão materialismo/pósmaterialismo é a melhor preditora dos conflitos ideológicos que fundamentam a DUDH (Pereira \& Camino, no prelo).

\section{MÉTODO}

\section{Participantes}

Participa neste estudo uma amostra composta por 300 estudantes, de um universo de 24.615 alunos regularmente matriculados, de ambos os sexos de uma universidade particular da cidade de Goiânia. A idade dos participantes varia de 18 a 53 anos $(M=24,7 ; D P$ $=7,76)$. Os dados foram coletados entre fevereiro $\mathrm{e}$ abril de 2002.

\section{Instrumentos}

As representações dos DHs são verificadas com a escala desenvolvida por Spini e Doise (1998) para avaliar os princípios organizadores do envolvimento nesses direitos: pessoal-concreto, pessoal-abstrato, governamental-concreto e governamental-abstrato. Utilizou-se a versão adaptada e validada nos estudos desenvolvidos por Pereira (2000) e Pereira e Camino (no prelo). Esse instrumento solicita aos participantes que pensem sobre "Direitos Humanos em Geral". Em seguida, são apresentadas as seguintes afirmações concernentes a esses direitos: "Eu deveria fazer muito para a aplicação desses direitos"; "O governo brasileiro empenha-se suficientemente para fazer aplicar esses direitos"; "Eu me empenho suficientemente para a aplicação desses direitos"; "O governo brasileiro deveria fazer muito para aplicação desses direitos"; "Eu poderia fazer muito para aplicação desses direitos"; "O governo brasileiro está fazendo atividades concretas para aplicação desses direitos"; "Eu invisto de uma maneira concreta para fazer aplicar esses direitos"; "O governo brasileiro poderia fazer muito para a aplicação desses direitos"; "O governo brasileiro teria que fazer muito para aplicação desses direitos"; "Eu teria que fazer muito para aplicação desses direitos"; "Eu estou fazendo atividades concretas de aplicação desses direitos"; "O governo brasileiro tem feito muito para aplicação desses direitos". Os estudantes indicaram, numa escala variando de 1 (discordo totalmente) a 7 (concordo 
totalmente), o seu grau de concordância com as afirmações.

Os sistemas de valores são analisados através do QVP-24, desenvolvido nos estudos realizados por Pereira e cols. (2001) e Pereira, Camino e cols. (2001). Este instrumento contém uma lista com 24 valores avaliados pelos estudantes, com notas variando de zero a dez, em função da importância de cada valor para a construção de uma sociedade ideal. A análise do Escalamento Multidimensional e a Análise Hierárquica de Aglomerados confirmam a organização dos valores em quatro sistemas: materialista (autoridade, lucro, riqueza e status); religioso (obediência às leis de Deus, religiosidade, salvação da alma e temor a Deus); hedonista (prazer, sensualidade, sexualidade e uma vida excitante); pósmaterialista. O sistema pós-materialista é constituído de três subsistemas: bem-estar individual (alegria, amor, auto-realização e conforto), bem-estar social (fraternidade, igualdade, justiça social e liberdade) e bem-estar profissional (competência, dedicação ao trabalho, realização profissional e responsabilidade). A análise da consistência interna desses sistemas revela os seguintes coeficientes: sistema religioso (alfa $=0,84)$; sistema materialista $($ alfa $=0,84)$; sistema hedonista (alfa $=0,82$ ); sistema pós-materialista (alfa $=0,85)$. Estes coeficientes permitem a construção de indicadores de adesão dos estudantes aos quatro sistemas de valores.

\section{PROCEDIMENTOS}

Os questionários foram aplicados coletivamente por dois pesquisadores em salas de aula contendo de 30 a 40 alunos. As salas foram previamente definidas através de sorteio, levando-se em conta as proporções de alunos de Ciências Humanas, Biológicas e Exatas, assim como as proporções de alunos matriculados em disciplinas de início, meio e final de curso. Os estudantes responderam aos questionários individualmente, num intervalo de tempo que variou de quinze a vinte minutos. Não se observaram recusas por parte dos participantes em responder aos questionários.

\section{RESULTADOS}

Para analisar os princípios organizadores do envolvimento nos DHs, aplicou-se uma análise fatorial, pelo método dos eixos principais, aos escores dos posicionamentos dos estudantes na escala de envolvimento nesses direitos (Tabela 1). Os resultados mostram os quatro princípios hipotetizados: pessoalabstrato; pessoal-concreto; governamental-abstrato; governamental-concreto: Como se pode constatar, os itens da escala são organizados adequadamente nos fatores esperados. A análise da fidedignidade das escalas revela coeficientes alfa variando entre $0,72 \mathrm{e}$ 0,75, o que permite a construção de indicadores do posicionamento dos estudantes nos quatro princípios organizadores encontrados.

Tabela 1. Cargas Fatoriais, Comunalidades $\left(\mathrm{h}^{2}\right)$, Eigenvalues, Variância Explicada e Fidedignidade da Escala sobre o Envolvimento nos Direitos Humanos

\begin{tabular}{|c|c|c|c|c|c|}
\hline \multirow[b]{2}{*}{ Itens Abreviados da Escala } & \multicolumn{4}{|c|}{$\begin{array}{c}\text { Princípios } \\
\text { Organizadores }\end{array}$} & \multirow[b]{2}{*}{$\mathbf{h}^{2}$} \\
\hline & F1 & $\mathbf{F 2}$ & $\mathbf{F 3}$ & F4 & \\
\hline O governo brasileiro deveria fazer muito para aplicação... & 0,82 & & & & 0,71 \\
\hline O governo brasileiro teria que fazer muito para... & 0,55 & & & & 0,38 \\
\hline O governo brasileiro poderia fazer muito para aplicação... & 0,55 & & & & 0,46 \\
\hline Eu poderia fazer muito para aplicação desses direitos & & 0,84 & & & 0,77 \\
\hline Eu deveria fazer muito para aplicação desses direitos & & 0,57 & & & 0,50 \\
\hline Eu teria que fazer muito para aplicação desses direitos & & 0,56 & & & 0,43 \\
\hline Eu invisto de uma maneira concreta para... & & & 0,86 & & 0,77 \\
\hline Eu estou fazendo atividades concretas de aplicação desses... & & & 0,63 & & 0,45 \\
\hline Eu me empenho suficientemente para aplicação desses... & & & 0,56 & & 0,33 \\
\hline O governo brasileiro está fazendo atividades concretas... & & & & 0,73 & 0,55 \\
\hline O governo brasileiro tem feito muito para ... & & & & 0,68 & 0,51 \\
\hline O governo brasileiro empenha-se suficientemente... & & & & 0,58 & 0,44 \\
\hline Eigenvalue & 1,61 & 1,60 & 1,57 & 1,51 & \\
\hline Variância Explicada (\%) & 13,4 & 13,3 & 13,1 & 13,0 & \\
\hline Fidedignidade (Alfa) & 0,72 & 0,75 & 0,75 & 0,72 & \\
\hline
\end{tabular}

Em seguida, foram analisadas as médias dos posicionamentos nos princípios organizadores através de uma análise de variância com medidas repetidas, a qual testou a combinação entre as duas dimensões subjacentes a esses princípios: tipo de envolvimento (pessoal ou governamental) versus nível de envolvimento (abstrato ou concreto). Os resultados revelam que os efeitos principais do tipo e do nível de envolvimento são significativos, $F(1,299)=19,60, \mathrm{p}$ $<0,001$ e $F(1,299)=960,02, p<0,001$, respectivamente. No geral, os estudantes consideram que seu envolvimento na aplicação dos DHs $(M=4,6$; $D P=0,80)$ é superior ao do governo $(M=4,4 ; D P=$ $0,64)$. Eles também percebem que o envolvimento concreto $(M=3,3 ; \mathrm{DP}=0,86)$ é inferior ao abstrato $(M=5,6 ; D P=0,88)$. Estes efeitos principais são qualificados pelo efeito de interação significativo entre os tipos e os níveis de envolvimento, $F(1,299)=$ $283,49, p<0,001$. Além disso, todas as diferenças entre as médias são significativas segundo o teste de Scheffé $(p<0,05)$. Como se pode constatar (Figura 1), 
no nível concreto, os participantes percebem que estão mais envolvidos $(M=3,8 ; D P=1,08)$ do que o Governo Brasileiro $(M=2,8 ; D P=1,07)$. Ao contrário, no nível abstrato, eles julgam que o governo deveria se envolver mais com a promoção dos $\mathrm{DH}(M$ $=5,9 ; D P=0,97)$ do que eles próprios $(M=5,3 ; D P=$ $1,09)$.

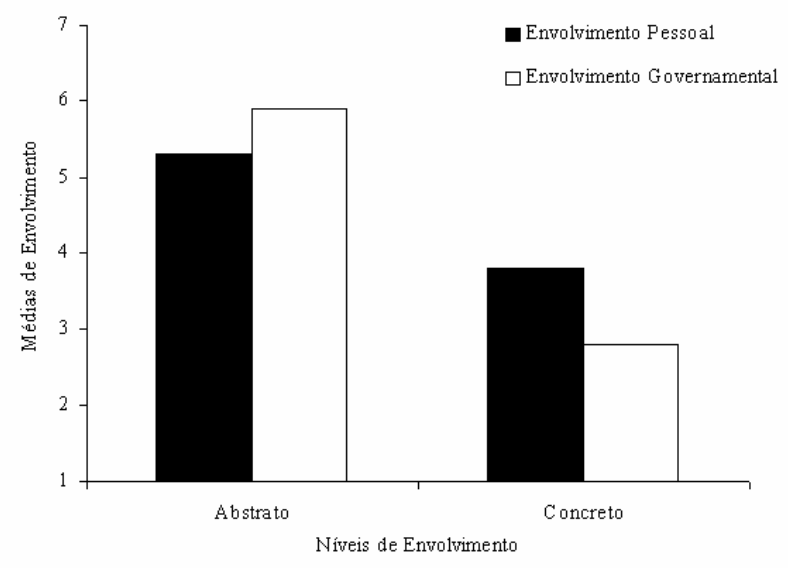

Figura 1. Médias da Percepção de Envolvimento nos DH em Função dos Níveis e dos Tipos de Envolvimento

Para averiguar como os sistemas de valores ancoram as representações do envolvimento nos DHs, foram aplicadas quatro regressões múltiplas pelo método stepwise, considerando os princípios organizadores do envolvimento nos DHs como variáveis-critério e os sistemas de valores como variáveis antecedentes. Os resultados mostram a existência de modelos de regressão significativos para todos os princípios organizadores: pessoal-abstrato, $R$ $=0,26 ; R^{2}=0,07 ; F(2,297)=10,412 ; p<0,001$; pessoal-concreto, $\mathrm{R}=0,18 ; \mathrm{R}^{2}=0,03 ; F(1,297)=$ 10,095; $p<0,01$; governamental-abstrato, $R=0,31 ; R^{2}$ $=0,10 ; F(2,297)=15,804 ; \mathrm{p}<0,001 ;$ governamentalconcreto, $R=0,19 ; R^{2}=0,04 ; F(2,297)=5,526 ; p<$ 0,01 . Esses resultados indicam que os sistemas de valores ancoram o posicionamento dos estudantes nos princípios organizadores do envolvimento nos DHs.

Tabela 2. Coeficientes de Regressão Padronizados Verificados na Análise da Ancoragem Social dos Princípios Organizadores do Envolvimento nos Direitos Humanos

\begin{tabular}{lcccc}
\hline & \multicolumn{3}{c}{$\begin{array}{c}\text { Princípios Organizadores do Envolvimento } \\
\text { nos Direitos Humanos }\end{array}$} \\
\cline { 2 - 5 } & \multicolumn{3}{c}{ Pessoal } & \multicolumn{2}{c}{ Governamental } \\
& Abstrato & Concreto & Abstrato & Concreto \\
\cline { 2 - 5 } Variáveis Antecedentes & Beta & Beta & Beta & Beta \\
\hline Sistema Pós-Materialista & $0,24^{* * *}$ & 0,02 & $0,29 * * *$ & $-0,02$ \\
Sistema Materialista & $-0,15^{*}$ & 0,03 & $-0,18^{* *}$ & $0,21^{* *}$ \\
Sistema Religioso & 0,04 & $0,18^{* *}$ & $-0,03$ & 0,07
\end{tabular}

Sistema Hedonista

$-0,07$

$-0,04$

0,11

$-0,17^{*}$

Nota. O posicionamento nos princípios organizadores varia de 1 (discorda totalmente) a 7 (concorda totalmente). A adesão aos valores varia de 0 (menor adesão) a 10 (maior adesão). * $p<0,05 ; * * p<0,01$; *** $p<0,001$.

A análise dessa ancoragem revela (Tabela 2) que o envolvimento pessoal-abstrato está ancorado na oposição entre os valores pós-materialistas e materialistas. A adesão ao sistema pós-materialista contribui com o aumento do envolvimento pessoalabstrato, enquanto a adesão aos valores materialistas diminui esse envolvimento. Essa oposição também ancora a percepção de envolvimento governamentalabstrato. Quanto maior é a adesão aos valores pósmaterialistas, mais elevada é a percepção de que o governo deveria se envolver com a aplicação dos DHs. Em contrapartida, a adesão aos valores materialistas contribui com a percepção de que o governo não deveria se envolver com os DHs. Os resultados também revelam que o envolvimento pessoal-concreto está ancorado apenas no sistema religioso, de modo que quanto maior a adesão aos valores desse sistema, maior é o grau de percepção dos estudantes de que eles estão concretamente envolvidos com a promoção dos DHs. Finalmente, a percepção de envolvimento governamental-concreto está ancorada na oposição entre valores materialistas e hedonistas. Quanto maior é a importância dada aos valores materialistas e menor a atribuída aos hedonistas, mais elevado é o grau de percepção de que o governo brasileiro está concretamente envolvido com a aplicação dos DHs.

\section{DISCUSSÕES}

Os resultados confirmam a existência dos quatro princípios organizadores subjacentes à representação do envolvimento nos DHs. De acordo com Spini (1997), esses princípios representam as duas dimensões conceituais que orientam os debates sobre a responsabilidade pela aplicação dos DHs: governamental-pessoal; abstrato-concreto. A primeira dimensão é formada pela crença de que a aplicação dos DHs deve ser dos países membros da ONU (Spini \& Doise, 1998). De fato, o preâmbulo da DUDH atribui essa responsabilidade aos governos, pois essa declaração foi viabilizada por um acordo entre os representantes dos Estados-Membros da ONU que "se comprometeram a promover, em cooperação com as Nações Unidas, o respeito universal aos direitos humanos e liberdades fundamentais e a observância desses direitos e liberdades" (Resolução 217 da ONU, 1948). A atribuição dessa responsabilidade aos Estados está presente na representação de 
universitários de vários países (Spini, 1997). Por outro lado, a visão ativista dos DHs é formada pela crença de que a aplicação desses direitos também é de responsabilidade dos indivíduos. Essa visão surge da necessidade de a sociedade civil exigir dos governos a ampla observância dos DHs. De fato, a inserção dos indivíduos em organizações não governamentais e em movimentos populares tem aumentado o sentimento de responsabilidade pessoal com a aplicação dos direitos (Pereira, 2000). Ao reconhecer essa possibilidade, a ONU institucionaliza a necessidade da participação individual na promoção dos DHs (United Nations, 1993).

A segunda dimensão é formada pelos diferentes níveis do envolvimento e descreve as crenças sobre o que deveria ser versus o que realmente é feito pela aplicação dos DHs. O processo psicossocial subjacente aqui é a dissociação entre o sentimento de desejabilidade do cumprimento dos DHs e a percepção dos estudantes sobre as suas ações e as do governo relativamente à aplicação concreta desses direitos. Essa dissociação reflete o processo que leva as pessoas a apresentar graus elevados de concordância com os princípios gerais e abstratos descritos na DUDH e, por outro lado, a discordar de ações concretas e objetivas que envolvem a aplicação prática desses princípios (Doise e cols., 1991). Um processo semelhante é explicitado no âmbito das novas teorias sobre o racismo. De fato, Pereira, Torres e Almeida (2003) constataram que as normas antiracistas levam os indivíduos a considerarem-se nãoracistas e a concordarem que brancos e negros devam ter direitos iguais. Paradoxalmente, esses mesmos indivíduos tendem a contratar uma funcionária branca, discriminando uma negra, quando as relações raciais são concretamente retratadas num contexto em que as questões trabalhistas estão salientes.

A interação entre as dimensões, além de confirmar os quatro princípios organizadores hipotetizados (Spini \& Doise, 1998), estão em consonância com o pressuposto básico da teoria das representações sociais que relaciona conhecimento institucionalizado e saber de senso comum (Moscovici, 1978). Isso significa que os grupos sociais transformam teorias institucionalizadas (Staerklé, Clémence \& Doise, 1998), como os DHs (Clémence \& Doise, 1995; Clémence, Doise, De Rosa \& Gonzalez, 1995), em conhecimentos úteis para o desenrolar da vida cotidiana e para a funcionalidade da comunicação social (Moscovici, 1988).

A análise dos posicionamentos nos quatro princípios mostra que os estudantes goianos percebem que estão concretamente mais envolvidos nos DHs que o governo, mas acham que o governo deveria se envolver mais do que eles. Esse padrão de resultados é igual ao constatado em universitários paraibanos (Camino \& cols., no prelo; Pereira \& Camino, no prelo), mas difere em um aspecto importante dos verificados na Suíça. Os estudantes suíços também percebem que o governo deveria se envolver mais que eles, mas acreditam que seu envolvimento concreto é igual ao do governo de seu país. Comparados com os estudantes brasileiros, os suíços apresentam uma visão mais positiva do seu governo. Tanto no estudo apresentado aqui quanto nos realizados por Pereira (2000), a adesão dos estudantes brasileiros aos princípios abstratos de envolvimento é elevada e a variabilidade é baixa. A baixa variância também é constatada nos princípios de envolvimento concreto, principalmente a percepção de envolvimento do governo.

Duas explicações podem elucidar as diferenças nas representações do envolvimento nos DHs de universitários brasileiros e suíços. A primeira refere-se ao fato de os estudantes brasileiros, historicamente, apresentarem uma visão negativa do governo (Da Costa, Torres, Burity \& Camino, 1994; Sanfelice, 1986). A segunda explicação coloca em relevo as representações sociais sobre países desenvolvidos e subdesenvolvidos. De fato, no estudo realizado por Staerklé e cols. (1998) os participantes percebem que os governos de países desenvolvidos respeitam os DHs; já nos países ditos do Terceiro Mundo, com governos autoritários ou tradicionalmente pouco democráticos, a violação a esses direitos é freqüente. É importante notar que essa percepção é essencialmente ideológica, pois nos países desenvolvidos essas violações são freqüentemente denunciadas pela Anistia Internacional (Pereira \& Camino, no prelo).

Mesmo servindo de base para a compreensão de uma série de relações sociais (Camino, Silva, Machado \& Pereira, 2001), a dimensão países desenvolvidos versus não desenvolvidos não é suficiente para explicar a variabilidade dos posicionamentos frente aos DHs. Essa compreensão passa pela ancoragem social dos princípios organizadores. A análise da ancoragem mostra, em síntese, que os valores pós-materialistas aumentam o sentimento de responsabilidade com os DHs, ao passo que os valores materialistas associam-se à crença de que nem as pessoas nem o governo devem se envolver com esses direitos. Com relação aos níveis de envolvimento concreto, a pouca importância dada ao sistema materialista, associada à adesão elevada ao sistema hedonista, leva a avaliação mais crítica do 
envolvimento do governo. Com relação ao envolvimento pessoal, apenas os estudantes com adesão elevada ao sistema religioso tendem a se considerar como concretamente envolvidos com os DHs. Esses resultados confirmam em parte as hipóteses levantadas. Confirmam apenas parcialmente porque a relação entre o sistema religioso e a percepção de envolvimento pessoal-concreto contradiz estudos anteriores (Clémence \& cols., 1995). Já a relação entre valores hedonistas e visão negativa do Governo Brasileiro encontra respaldo em investigações prévias, pois estudantes universitários que aderem a valores relacionados à abertura à mudança e à busca do prazer tendem a avaliar negativamente os excessos governamentais contrários aos princípios subjacentes aos DHs (Spini, 1997).

Spini (1997) mostra que valores pós-materialistas, avaliados com o inventário elaborado por Schwartz (1992), contribuem com o sentimento de responsabilidade pessoal com os DHs, enquanto os valores materialistas diminuem esse sentimento. Uma lógica oposta a essa foi verificada em relação à percepção do envolvimento dos governos. A reinterpretação dos tipos motivacionais à luz da teoria de Inglehart (1991), realizada por Spini, mostra a importância do posicionamento ideológico na compreensão dos DHs e permite interpretações similares às constatadas em outras investigações (Diaz-Veizades, Widaman, Little \& Gibbs, 1995; Pereira \& Camino, no prelo). Essas interpretações reforçam a relação entre estrutura de valores e estruturas ideológicas.

De fato, a compreensão da natureza dos valores e o envolvimento nos DHs se relacionam com a participação política das pessoas (Pereira, 2000). O envolvimento nos DHs está associado à participação em manifestações políticas, as quais são, na maioria das vezes, de oposição às violações dos DHs praticadas pelos governos. Nesse sentido, posicionarse contrariamente ao Governo Brasileiro parece refletir uma visão positiva dos DHs e uma adesão mais ampla aos princípios democráticos. Essa interpretação, embora não possa ser testada com os dados apresentados, está em consonância com os resultados da pesquisa transcultural realizada por Clémence e cols. (1995), a qual mostra que a visão mais ampla dos DHs é própria das pessoas com posicionamento contrário ao controle do Estado. São, sobretudo, os valores que compõem o sistema pós-materialista que estão na base dos princípios democráticos (Inglehart, 1994). De fato, pesquisas realizadas no Brasil mostram que estudantes que priorizam valores materialistas e rejeitam os pós-materialistas não estão vinculados às instituições políticas e não participam em atividades de protesto sociopolítico (Lima, 1997; Lima \& Camino, 1995; Pereira \& cols., 2001). Assim, a relação entre valores e DHs parece tratar da maneira como eles se associam aos ideais democráticos.

Finalmente, o estudo apresentado neste artigo e as referências às investigações anteriores são concernentes a pesquisas realizadas na vigência do governo Fernando Henrique Cardoso. Isto indica que as interpretações realizadas sobre as representações do envolvimento do governo devem ser criteriosamente questionadas, sobretudo quanto a sua adequação à percepção do envolvimento do governo atual. Este governo é formado por uma base partidária historicamente identificada como de esquerda, cujas bases são formadas por várias organizações não governamentais e movimentos estudantis, os quais são ativistas na luta pelos DHs. Novos estudos podem ser planejados com o objetivo de verificar, na vigência do governo de Luiz Inácio Lula da Silva, as representações do envolvimento nesses direitos.

\section{REFERÊNCIAS}

Abric, J. (1994). L’organisation interne des représentations sociales: système central et système périphérique. Em C. Guimelli (Org.), Structures et transformations des représentations sociales (pp. 73-84). Neuchâtel: Delachaux et Niestlé.

Álvaro, J. L. (1995). Psicología social: perspectivas teóricas y metodológicas. Madrid: Siglo XXI.

Billig, M. (1991). Ideology and opinions: studies in rhetorical psychology. London: Sage.

Camino, L. (2000). Direitos humanos e psicologia. Em Conselho Federal de Psicologia (Org.), Psicologia, ética e direitos humanos. (pp. 41-65). São Paulo: CFP.

Camino, C., Camino, L., Pereira, C. \& Paz, M. (no prelo). Moral, direitos humanos e inserção social. Estudos de Psicologia.

Camino, L., Silva, P., Machado, A. \& Pereira, C. (2001). A face oculta do racismo no Brasil: uma análise psicossociológica. Revista de Psicologia Política, 1 (1), 13-36.

Cardia, N. (1995). Direitos humanos e exclusão moral. Sociedade e Estado, 2 (2), 343-389.

Clémence, A. \& Doise, W. (1995). La représentation sociale de la justice: une approche des droits dans la pensée ordinaire. L'Année Sociologique, 45 (2), 371-400.

Clémence, A., Doise, W., De Rosa, A., S. \& Gonzalez, L. (1995). La représentation sociale des droits de l'homme: Une recherche internationale sur l'étendue et les limites de l'universalité. Journal Internationale de Psychologie, 30 (2), 181-212.

Cranston, M. (1979). O que são os direitos humanos? Rio de Janeiro: DIFEL.

Da Costa, J. B. (2000). Visões sociais de democracia: um estudo psicossociológico dos significados da democracia. 
Tese de Doutorado Não-Publicada, Programa de PósGraduação em Psicologia Social, Pontifícia Universidade Católica de São Paulo.

Da Costa, J. B., Torres, A. R., Burity, M. H. \& Camino, L. (1994). Universidade: espaço institucional para o desenvolvimento político. Temas de Psicologia, 1 (1), 1736.

Diaz-Veizades, J., Widaman, K. F., Little, T. D. \& Gibbs, K. W. (1995). The measurement and structure of human rights attitudes. Journal of Social Psychology, 135 (2), 313-328.

Doise, W. (1986). Les represésentations sociales: définition d'un concept. Em W. Doise \& A. Palmonari (Orgs.), $L^{\prime}$ étude des représentations sociales (pp. 81-94). Paris: D\&N.

Doise, W. (1993). Debating social representations. Em G. M. Breakwill \& D. V. Canter (Orgs.), Empirical approaches to social representations. (pp. 157-170) Londres: Academic Press.

Doise, W. \& Herrera, M. (1994). Déclaration universelle et représentations sociales des droits de l'homme: une étude à Genève. Revue Internationale de Psychologie Sociale, 4 (1), 87-107.

Doise, W., Clémence, A. \& Lorenzi-Cioldi, F. (1993). The quantitative analysis of social representations. Hempel Hempstead: Harvester Wheatsheaf.

Doise, W., Dell'Ambrogio, P. \& Spini, D. (1991). Psychologie sociale et droit de l'homme. Revue Internationale de Psychologie Sociale, 4 (2), 257-277.

Doise, W., Staerklé, C., Clémence, A. \& Savory, F. (1998). Human rights and genevan youth: a developmental study of social representatios. Swiss Journal of Psychology, 57 (1), 86-100.

Gouveia, V., Martínez, E., Meira, M. \& Milfont, T. L. (2001). A estrutura e o conteúdo universais dos valores humanos: análise fatorial confirmatória da tipologia de Schwartz. Estudos de Psicologia, 6 (2), 133-142.

Herrera, M., Lavalée, M. \& Doise, W. (2000). Human rights and politics: a social representational analysis of political positioning during the 1995 Quebec sovereignty campaign. Group Processes \& Intergroup Relations, 3 (1), 25-40.

Inglehart, R. (1977). The silent revolution. Princeton: University Press.

Inglehart, R. (1991). El cambio cultural en las sociedades industriales avanzadas. Madrid: Siglo XXI.

Inglehart, R. (1994). Modernización y post-modernización: la cambiante relación entre el desarrollo económico, cambio cultural y político. Em J. D. Nícolas \& R. Inglehart (Orgs.), Tendencias mundiales de cambio en los valores sociales y políticos (pp. 157-170). Madrid: Fundesco.

Jahoda, G. (1988). Critical notes and reflections on social representations. European Journal of Social Psychology. 18 (2), 198-209.

Leyens, J. P. \& Dardenne, B. (1996). Basic concepts and approaches in social cognitions. Em M. Hewstone, W. Stroebe \& G. M. Sterphenson (Orgs.), Introduction to social psychology: a European perspective (pp. 109-134). Oxford: Blackwell Publishers.

Jodelet, D. (1989). Folies et représentations sociales. Paris: PUF.
Lima, M. E. (1997). Valores, participação política, atitudes em face da democracia e ao autoritarismo: uma análise da socialização política dos universitários da Paraíba. Dissertação de Mestrado Não-Publicada, Universidade Federal da Paraíba, João Pessoa.

Lima, M. E. \& Camino, L. (1995). A Política na vida de estudantes universitários. Em M. J. L. Silva (Org.), Iniciados (pp. 11-35). João Pessoa: Editora Universitária.

Menezes, I. \& Campos, B. (1997). The process of valuemeaning construction: a cross-sectional study. European Journal of Social Psychology, 27 (1), 55-77.

Moscovici, S. (1978). A representação social da psicanálise. Rio de Janeiro: Zahar.

Moscovici, S. (1988). Notes towards a description of social representations. European Journal of Social Psychology, 18 (2), 211-250.

Pereira, C. (2000). Representações sociais do envolvimento nos direitos humanos. Dissertação de Mestrado Não-Publicada, Programa de Pós-Graduação em Psicologia Social, Universidade Federal da Paraíba, João Pessoa.

Pereira, C. \& Camino, C. (no prelo). Representações sociais, envolvimento nos direitos humanos e ideologia política em estudantes universitários de João Pessoa. Psicologia: Reflexão e Crítica.

Pereira, C. \& Soares, A. (2003). Reflexões acerca da perspectiva das representações sociais. Estudos, 30 (1), 6184.

Pereira, C., Camino, L., Da Costa, J., Lima, M. E., Lhullier, L. \& Sandoval, S. (2001). Sistemas de valores e atitudes democráticas de estudantes universitários do Sul do Brasil. Estudos, 28 (4), 639- 671.

Pereira, C., Lima, M. E. \& Camino, L. (2001). Sistemas de valores e atitudes democráticas de estudantes universitários de João Pessoa. Psicologia: Reflexão e Crítica, 14 (1), 177-190.

Pereira, C., Torres, A. R. R. \& Almeida, S. T. (2003). O preconceito na perspectiva das representações sociais: análise da influência de um discurso justificador da discriminação no preconceito racial. Psicologia: Reflexão $e$ Crítica, 16 (1), 95-107.

Pereira, C., Torres, A. R. R. \& Barros, T. (2002). Sistemas de Valores e Atitudes Democráticas de Estudantes Universitários. (manuscrito não-publicado.)

Potter, J. \& Linton, I. (1985). Some problems underlying the theory of social representations. British Journal of Social Psychology, 24 (1), 81-90.

Resolução 217 da ONU, Nações Unidas, Assembléia Geral das Nações Unidas, III, 1948.

Rokeach, M. (1973). The nature of human values. New York: Free Press.

Sanfelice, J. (1986). Movimento estudantil. São Paulo: Cortez.

Schwartz, S. H. (1992). Universals in the content and structure of values: theoretical advanced and empirical testes in 20 countries. Em M. Zanna (Org.), Advanced in experimental social psychology (Vol. 25, pp. 1 - 65). Orlando: Academic Press.

Schwartz, S. H. (1994). Are there universal aspects in the structure and contents of human values? Journal of Social Issues, 50 (1), 19-45. 
Schwartz, S. H. \& Bardi, A. (2001). Value hierarchies across cultures: taking a similarities perspective. Journal of CrossCultural Psychology, 32 (2), 268-290.

Souza, L. (1996). O linchamento sob uma perspectiva psicossocial: identidade social e representação de justiça. Em L. Camino \& P. Menandro (Orgs.), A sociedade na perspectiva da psicologia: questões teóricas $e$ metodológicas (pp. 47-69). Vitória: ANPEPP.

Souza, L., Rosa, L., Effgen, H., Paiva, A., Toniato, M. \& Alvim, S. (1998). Direitos humanos e representação de justiça. Psicologia: Reflexão e Crítica, 11 (3), 497-510.

Spini, D. (1997). Valeurs et représentations sociales des droits de l'homme: une approche structurale. Thèse de Doctorat Non-Publieé, Faculté de Psychologie et des Sciences de l'Education, Universidade de Genebra. Genebra.

Spini, D. \& Doise, W. (1998). Organizing principles of involvement in human right and their social anchoring in values priorities. European Journal of Social Psychology, 28 (4), 603-622.
Staerklé, C., Clémence, A. \& Doise, W. (1998). Representation of human rights across different national contexts: the role of democratic and non-democratic populations and governments. European Journal of Social Psychology, 28 (2), 207-226.

Tamayo, A. \& Shwartz, S. H. (1993). Estrutura motivacional dos valores humanos. Psicologia: Teoria e Pesquisa, 9 (2), 328-346.

United Nations (1993). World conference on human rights: the Vienna declaration and programme of action. New York: United Nations.

Endereço para correspondência: Cícero Pereira, Grupo de Pesquisa em Processos Grupais, Caixa Postal 12900, CEP 74643-970, Goiânia, GO. E-mail: cicero.psi@ucg.br. 